\title{
Development of Noise Maps of Great City of Riyadh by Using LimA
}

\author{
Khalid A. Alsaif and Mosaad A. Foda
}

\begin{abstract}
Riyadh City, the capital of the Kingdom of Saudi Arabia, has been subjected to continual increase in road traffic due to overall increase in prosperity, fast development and expansion of economy. In this paper, the first round of noise mapping for Riyadh City is developed by using the Predictor-LimA 7810 software. Road traffic data were measured or estimated as accurate as possible in order to obtain reliable noise maps. The simulation results at some chosen locations are validated by actual field measurements, which are obtained by a system that consists of a sound level meter, a GPS receiver and a database to manage the measured data. The maps show that noise levels remain over $50 \mathrm{dBA}$ and can exceed $70 \mathrm{dBA}$ at the nearside of major roads and highways.
\end{abstract}

Index Terms-Noise pollution, road traffic noise, LimA predictor, GPS.

\section{INTRODUCTION}

Riyadh City is a vibrant community that comprises extended urbanized areas in all directions. The city is supporting residential populations, shopping centers and an active commerce. It has grown rapidly in the last years, attracting new residents, residential areas expand, and it is expected that this growth will continue in the future. In particularly, more and more people are choosing to live in Riyadh City. The estimated population is more than 8.8 million by the end o year 2014. With this fundamental shift in the demographic comes the potential between lifestyle and the intrusion of existing or future noise sources in the community. These lead to increase in noise pollution like big cities in other parts of the world. Therefore, measures for the management and reduction of noise are seemed to be necessary. The road traffic is the main source of noise. The main roads are over loaded with traffic flow of different composition. The traffic statistics for the year 2012 showed that approximately 1.2 million vehicles move in its street daily. $90 \%$ of this volume is private cars, $1 \%$ is taxis/limousines. These vehicles travel in the streets in the peak period from 7:00 o'clock in the morning to 3:00 o'clock afternoon, then from after Aser prayer until 10:00 PM. The daily estimated traffic volume is approximately equal 6.5

Manuscript received June 19, 2014; revised October 18, 2014. This work is supported by the National Plan for Science and Technology (NPST-KSU) at King Saud University, Saudi Arabia, grant \#10-ENV1182-02.

The authors are with the Mechanical Engineering Department, King Saud University, Saudi Arabia and King Abdulaziz City for Science and Technology, Riyadh, Saudi Arabia (e-mail: alsiaf@ksu.edu.sa, mfoda@ksu.edu.sa). million vehicle trips. This will increase to 15 million by the year 2020. Traffic noise in the city is generally different in nature and characteristics. Furthermore, it is potentially different from that in other countries because of different types of vehicles, different levels of vehicular maintenance, and possibly different ways of driving behavior. Therefore, traffic noise has been identified as the most pervasive and most acutely perceived negative impact of transportation on the quality of life for residents living next to highways and heavy traffic roads. In studies conducted in developed countries, road traffic noise is considered to be the worst environmental noise offender and a leading detriment to health and well-being in the community [1]. But in some developing countries, noise has not yet been recognized as a major problem, however; studies carried out in some of these countries show the potentially adverse effects of noise in communities where road traffic noise is very intensive. For example, in Saudi Arabia, it was reported that the sound pressure level can goes up to $90 \mathrm{~dB}$ in Jeddah [2], [3]. In Egypt, a five year plan (2007-2012) has been developed to reduce noise to the safe level set by the Egyptian Law 4/1994. Eleven ministries coordinated by MSEA are working to implement the elements of the plan. A national noise monitoring network (NNMN) consists of thirty stations has been established starting by Greater Cairo city and first operated in March 2007 [4]. Noise is also a major environmental problem in Nigeria, with traffic noise bothering the people most [5], [6]. In Vietnam, Phan et al. [7], [8] conducted a large-scale socio-acoustic survey of community response to road traffic noise in Hanoi and Ho Chi Minh cities to investigate human reactions to road traffic noise in these two Vietnamese large cities. The noise exposure level $\left(\mathrm{L}_{\mathrm{den}}\right)$ equals $75-83 \mathrm{~dB}$. Compared to annoyance responses of European people, Vietnamese were less annoyed by road traffic noise by about $5 \mathrm{~dB}$. Xia et al. [9] suggested developing dynamic noise maps for developing cities in china. Theses noise mapping should be updated based on the changes of geographic information and traffic flows, and shows the trend of noise level in the region to be mapped. Tsai et al. [10] constructed noise maps for Tainan City in Taiwan to demonstrate the efficiency of noise mapping to investigate environmental noise. He analyzed the spatial characteristics of urban environmental noise by using noise maps produced at 345 noise monitoring stations noise data were collected at varying intervals: morning, afternoon, and evening in both summer and winter. The spatial distributions of the noise levels during each time interval were evaluated and visualized by geographic information systems. The results of noise exposure analysis showed that over $90 \%$ of the Tainan City population are exposed to unacceptable noise. 


\section{PREDICTION}

The LimA 7810 software system is used to generate the noise maps. It includes advanced automated data manipulation, geometric handling and allows the user to perform large and accurate noise calculations from existing data sets [11]. In addition, GIS software is incorporated with LimA to develop noise maps. The necessary data for the development of the noise maps for Riyadh City exists, but its disparity is similar to that in other foreign cities. We contacted many organizations such that Riyadh Municipality, ArRiyadh Development Authority, Riyadh Traffic Main Center, Ministry of Transportation, Ministry of Municipal and Rural Affairs, and different Riyadh Districts authorities to collect data. The traffic data is the most important. It contains the traffic volume (number of vehicles), vehicle category and vehicles speed. There are other sources that affect the level of noise emission such as width of roads and streets, number of lanes, road surface roughness and type of tires. In addition, building data and height model are obtained. The input data for the simulation LimA software are stored in Access tables, which are connected to the AutoCAD drawings using the entities handle. The base map layers are imported in LimA through DXF files. For the buildings, the height information is sent as color property (the conversion between thickness and color was done previously on the AutoCAD drawing). After importing the geometry, some checks should be done in LimA: closing polygons to ensure the correct modeling, especially for buildings; recognizing and preventing multiple existences of objects; linking objects to prevent gaps in the model; smoothing polygons to reduce the number of vectors and speed up calculations. The noise mapping area is covering approximately $400 \mathrm{~km}^{2}$ with a perimeter of $78 \mathrm{~km}$. It is divided into four regions. Each contains up to 39,800 grid points, the distance between points was 100 meters. The predicted noise level was calculated on the basis of the input data with a calculation height $2 \mathrm{~m}$ above terrain. The road traffic lanes were divided into two groups. The first one is with the measured traffic data and the second with the predicted traffic data. The road traffic speed used was speed limit taken from the traffic signs. For all obstacles, the constant reflection coefficient was used, except in the cases when the onsite review gives the basis for the peculiar value. The heights of the obstacles were determined based on the onsite review or the orthographic images. The buildings with the minimum plan area less than $10 \mathrm{~m}^{2}$ and height less than 2 $\mathrm{m}$, were neglected. The walls and fences with the height less than 2 meter, and the length less than $10 \mathrm{~m}$ are neglected. The longterm correction due to the meteorological conditions were taken into account by using the default values for the day (50\% favorable atmospheric conditions), evening (75\% favorable atmospheric conditions) and night (100\% favorable atmospheric conditions) period.

The calculation is very complex and time consuming; for a single run it taken almost 4 hours (only the running time, not including the data preparation and visualization of the results) on the appropriate workstation (HP ENVY; i7-4702MQ 2.2 GHz, 16 GB DDRAM2, 2000 GB HDD). The LimA model including input data, databases and corresponding results occupies 4.31 GB. The ISO noise color indicators are used for coloring. The noise map produced can be exported to DXF and SHP files with other modeling items, for post-processing in GIS software. The noise maps for the day, evening, night and for the whole day are presented in Fig. 1 to Fig. 4; respectively. The day-evening-night level $\mathrm{L}_{\mathrm{den}}$ is commonly used as the rating method to describe long-term annoyance from environmental noise [12].

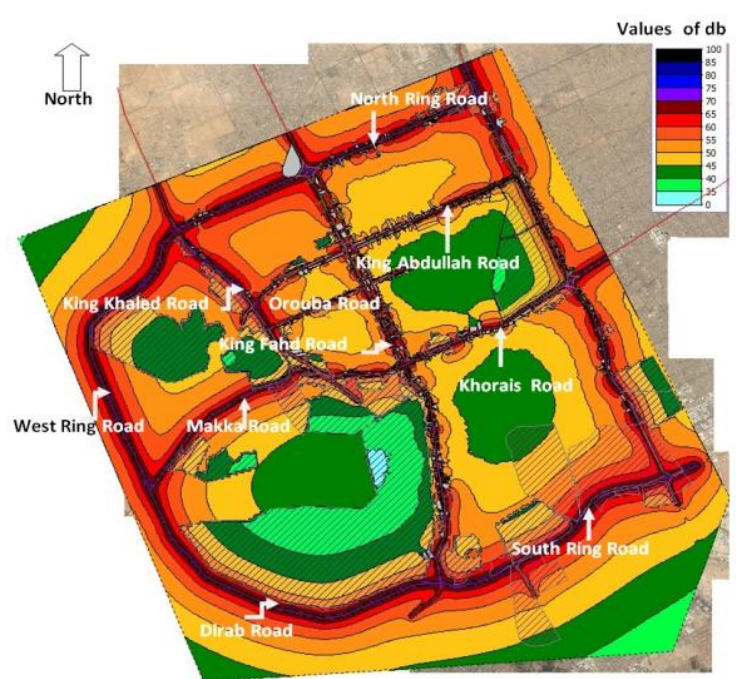

Fig. 1. $\mathrm{L}_{\text {day }}$ for Riyadh City (area encircled by first Ring Road).

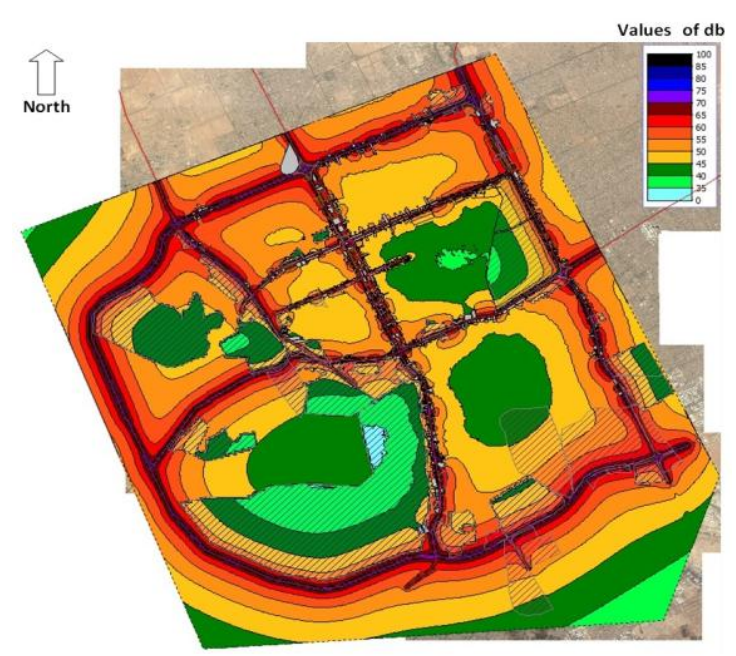

Fig. 2. Levening for Riyadh City (area encircled by first Ring Road).

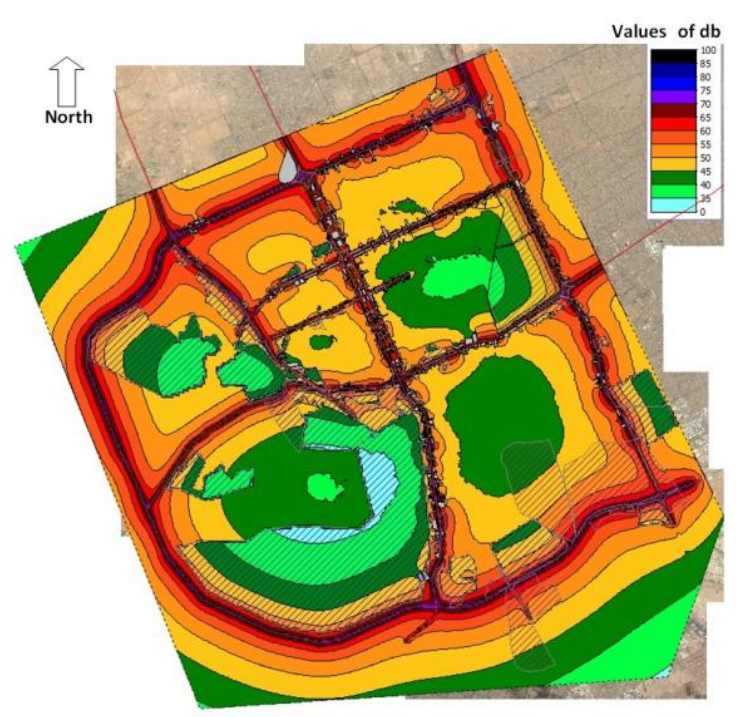

Fig. 3. $\mathrm{L}_{\text {night }}$ for Riyadh City (area encircled by first Ring Road). 


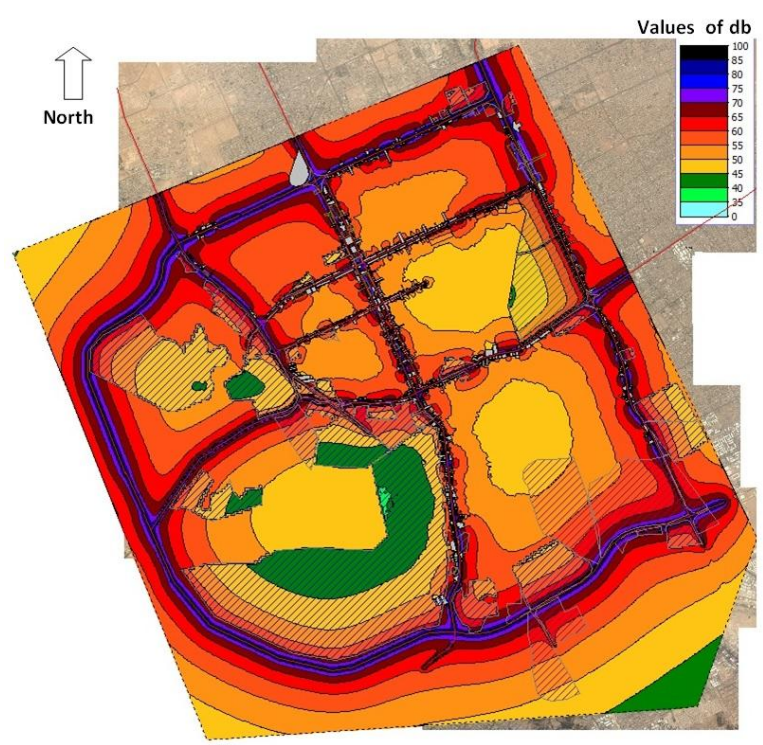

Fig. 4. $\mathrm{L}_{\mathrm{den}}$ for Riyadh City (area encircled by first Ring Road).

\section{VALIDATION AND RESULTS}

The short-term validation of the predicted noise levels was conducted through field measurements of the noise levels at selected locations in four zones (mostly near crossroads). These zones are Olyaa Street, Exit 5, Exit 6, and Exit 7. The locations were continuously monitored during working days for 15 minutes in the daytime hours and 15 minutes in the nighttime hours. The position of the measurement points is near the locations where the data for the road traffic volume, composition and speed are collected. In such way, the possibility of the crude errors of the presumed road traffic data is minimized. The measurements were done through April and May of 2014 using sound level meter Rion NL-32 with tripod and windshield. It has an internal disk for storing its application software, user-defined set-ups and measurement data consisting of the measured sound levels, measurement time, and position data imported from a GPS receiver. Calibration was performed internally or externally using NC-74 sound calibrator before each measurement. The spatial position of each observation point was determined using the hand held Garmin GPS with a precision of 5-10 meters in absolute point positioning. The coordinate of each observation point was recorded in geographic system (latitude and longitude) in the WGS84 global system. The measured data stored in the sound level meter, including concurrently evaluated sound levels such as $\mathrm{L}_{\mathrm{Aeq}}, \mathrm{L}_{\mathrm{AE}}, \mathrm{L}_{\mathrm{Amax}}$, $\mathrm{L}_{\mathrm{Amin}} \mathrm{L}_{90}, \mathrm{~L}_{50}, \mathrm{~L}_{10}$ and $\mathrm{L}_{5}$. After the first simulation was done and the first version of the noise map is ready, the values obtained were compared with the actual field measurements at chosen locations. It is presumed that a significant difference between the predicted and the measured noise levels exists if the difference exceeds $\pm 3 \mathrm{dBA}$. This is because the human ear has a logarithmic response to noise and $3 \mathrm{~dB}$ is about the smallest change that most people can detect. In case of the difference is greater than $\pm 3 \mathrm{~dB}$ (measurement versus simulation result), the input data was tuned and the calculation process was repeated until the differences become within $\pm 3 \mathrm{~dB}$.

The comparison between the calculated and measured noise levels results is presented in the Table I and Table II for
Olayaa Street (as an example). The differences between the measured and the predicted noise levels stay within $\pm 3 \mathrm{~dB}$ at all measuring locations in the four measuring zones except some locations with asterisk (seven locations out of sixty-eight). The discrepancies can be due to several reasons. The measured speed of vehicles in some streets is higher than the speed limit allowed by traffic signs, which is used in prediction. The data concerning the road surface type were poor; even it is one of the most important parameter for the noise calculation. On some locations, the input data for the road traffic composition was not completely correct, especially for the night period where there is high percentage of heavy vehicles. On the whole, the comparisons of the results obtained from the simulation with that obtained from actual field measurements show good agreement. Therefore, the graphic representation matches the real measurements.

TABLE I: DAYTIME SHORT-TERM VALIDATION OF NOISE LEVELS IN OLYAA STREET

\begin{tabular}{|c|c|c|c|c|}
\hline \multicolumn{2}{|c|}{$\begin{array}{l}\text { Measurement } \\
\text { Location }\end{array}$} & \multirow{2}{*}{$\begin{array}{l}\text { Predicted } \\
\mathrm{L}_{\text {day }} \\
\mathrm{dB}(\mathrm{A})\end{array}$} & \multirow{2}{*}{$\begin{array}{l}\text { Measured } \\
\mathrm{L}_{\text {day }} \\
\mathrm{dB}(\mathrm{A})\end{array}$} & \multirow{2}{*}{$\begin{array}{l}\Delta\left(\mathrm{L}_{\text {meas }}-\mathrm{L}_{\text {pred }}\right) \\
\mathrm{dB}(\mathrm{A})\end{array}$} \\
\hline $\mathrm{N}$ & $E$ & & & \\
\hline 24.40858 & 46.41502 & 71.6 & 67.8 & $-3.8^{*}$ \\
\hline 24.40997 & 46.41432 & 67.16 & 65.3 & -1.86 \\
\hline 24.41222 & 46.41320 & 69.8 & 71.5 & 1.7 \\
\hline 24.41365 & 46.41245 & 63.1 & 59.9 & $-3.2^{*}$ \\
\hline 24.41470 & 46.41196 & 66.4 & 62.6 & $-3.8^{*}$ \\
\hline 24.41689 & 46.41081 & 61.9 & 60.2 & -1.7 \\
\hline 24.41831 & 46.41010 & 62.6 & 64.5 & 1.9 \\
\hline 24.42185 & 46.40833 & 67.8 & 66.7 & -1.1 \\
\hline 24.42341 & 46.40754 & 69.2 & 67.8 & -1.4 \\
\hline 24.42719 & 46.40563 & 74 & 72.3 & -1.7 \\
\hline 24.42907 & 46.40467 & 69.08 & 67.6 & -1.48 \\
\hline 24.43276 & 46.40283 & 72.53 & 72.3 & -0.23 \\
\hline 24.43338 & 46.40249 & 69.2 & 67.9 & -1.3 \\
\hline 24.43464 & 46.40183 & 74.8 & 75.5 & 1.42 \\
\hline 24.43695 & 46.40067 & 70.3 & 71.9 & 1.6 \\
\hline
\end{tabular}

TABLE II: NIGHTTIME SHORT-TERM VALIDATION OF NOISE LEVELS IN

\begin{tabular}{|c|c|c|c|c|}
\hline \multicolumn{5}{|c|}{ OLYAA STREET } \\
\hline \multicolumn{2}{|c|}{$\begin{array}{c}\text { Measurement } \\
\text { Location }\end{array}$} & \multirow{2}{*}{$\begin{array}{l}\text { Predicted } \\
\mathrm{L}_{\text {night }} \\
\mathrm{dB}(\mathrm{A})\end{array}$} & \multirow{2}{*}{$\begin{array}{l}\text { Measured } \\
\mathrm{L}_{\text {night }} \\
\mathrm{dB}(\mathrm{A})\end{array}$} & \multirow[t]{2}{*}{$\begin{array}{l}\Delta\left(\mathrm{L}_{\text {meas }}-\mathrm{L}_{\text {pred }}\right) \\
\mathrm{dB}(\mathrm{A})\end{array}$} \\
\hline $\mathrm{N}$ & $\mathrm{E}$ & & & \\
\hline 24.40866 & 46.41498 & 73.64 & 70.1 & $-3.54^{*}$ \\
\hline 24.40996 & 46.41434 & 70.08 & 72.9 & 2.82 \\
\hline 24.41226 & 46.41318 & 73.62 & 74.5 & 0.88 \\
\hline 24.41365 & 46.41245 & 77.43 & 73.6 & $-3.83^{*}$ \\
\hline 24.41474 & 46.41193 & 75.92 & 74.3 & -1.62 \\
\hline 24.41689 & 46.41081 & 69.18 & 68.4 & -0.78 \\
\hline 24.41831 & 46.41010 & 69.98 & 69 & -0.98 \\
\hline 24.42184 & 46.40833 & 59.65 & 59.4 & -0.25 \\
\hline 24.42343 & 46.40752 & 58.34 & 55.5 & -2.84 \\
\hline 24.42721 & 46.40562 & 68.22 & 71.2 & 2.98 \\
\hline 24.42922 & 46.40460 & 72.19 & 71.6 & -0.59 \\
\hline 24.43288 & 46.40276 & 76.64 & 75.8 & -0.84 \\
\hline 24.43347 & 46.40243 & 71.0 & 76.9 & $5.9^{*}$ \\
\hline 24.43470 & 46.40180 & 78.75 & 76 & -2.75 \\
\hline 24.43700 & 46.40067 & 78.57 & 76.3 & -2.27 \\
\hline
\end{tabular}


The maps illustrate that the noise levels remain over 50 $\mathrm{dBA}$ and can exceed $70 \mathrm{dBA}$ at the nearside of major roads and highways. This is considered relatively high since the accepted level is $65 \mathrm{dBA}$ [13], [14]. One expects that those residents near highways and main roads suffer from excessive noise if windows of their houses are opened. It should be noted that this outdoor noise level can be decreased by about 25-30 dBA by using good housing acoustic isolation [15]. Another added note is that the height and shape of the surrounding buildings, facades,...etc always referred as city canyons are estimated because there are no sufficient documented information for the city of Riyadh. It is well known that the city canyons affect greatly the geo-statistical interpolation inherent in the prediction software. Therefore, the actual average noise level is less than what was obtained. But, in general, noise levels are less than that in many other big cities in other parts of the world. Fortunately, most of the Riyadh residents are not aware of the high level of outdoor noise because they do not use their outdoor balconies. In addition, the windows are almost always closed because of the use of air conditioning in all residence.

The results shown in these noise maps can be used by local decision makers and concerning officials to plan their infrastructure development programs. If not considered at early stage in the city planning and development, the noise problem could further increase, and probably, later mitigation measures will become extremely expensive to implement. The immediate, medium and long-term remedial action plans should be established.

\section{CONCLUSION}

Noise maps for Riyadh City using software LimA prediction which are validated by field measurements are developed. The field noise measurements and the noise maps representations are close to each other. The preliminary results of noise maps indicate that the noise measurements for day and night are relatively high in Riyadh City but it does not represent a significant problem. This is because the lack of the non-existence of exposure and/or annoyance analysis that show how many inhabitants affected by noise that exceeding the standard measure that is adopted in foreign countries. The responsible government should develop a complete legal system for Noise Abatement Act. This act should be able to follow the dynamic process of socio-economic development and to perceive, support and promote positive trends in the noise abatement procedures.

\section{ACKNOWLEDGMENT}

The work presented herein has been supported by the National Plan for Science and Technology (NPST-KSU) at King Saud University, grant \#10-ENV1182-02. This support is greatly appreciated.

\section{REFERENCES}

[1] B. Berglund and T. Lindvall, "Community noise- document prepared for the World Health Organization,” Arch Center Sensory Res., vol. 2, pp. 86-103, 1995.

[2] A. I. El-Sharkawy and A. A. Aboukhashaba, "Traffic noise measurement and analysis in Jeddah," Applied Acoustics, vol. 16, pp. 41-49, 1983.

[3] K. A. Alshorbagy, "Environmental acoustic and quality in Jeddah urban sites," Applied Acoustics, vol. 17, pp. 261-274, 1984.

[4] EAAA: Annual Report, Egyptian Environmental affairs Agency, 2007.

[5] M. U. Onuu and A. I. Menkiti, "Analysis of Nigerian community response to road traffic noise," Journal of Science and Engineering Technology, vol. 3, pp. 536-547, 1996.

[6] M. U. Onuu, "Road traffic noise in Nigeria: measurements, analysis and evaluation of nuisance," Journal of Sound and Vibration, vol. 233 , pp. 391-405, 2000.

[7] H. Y. T. Phan, T. Yano, H. A. T. Phan, T. Nishimura, T. Sato, and Y. Hashimoto, "Social survey on community response to road traffic noise in Hanoi and Ho Chi Minh City," in Proc. ICBEN, Foxwoods, CT, 2008.

[8] H. Y. T. Phan, T. Yano, H. A. T. Phan, T. Nishimura, T. Sato, and Y. Hashimoto, "Community responses to road traffic noise in Hanoi and Ho Chi Minh City," Applied Acoustics, vol. 71, pp. 107-114, 2010.

[9] D. Xia, Y. Zhou, W. Zhu, and W. Zhang, "Study on noise mapping in developing Cities," Journal of Acoustical Society of America, vol. 131, 2012.

[10] K.-T. Tsai, M.-D. Lin, and Y.-H. Chen, "Noise mapping in urban environments: A Taiwan study," Applied Acoustics, vol. 70, pp. 964-972, 2009.

[11] Brüel \& Kjær. [Online]. Available: http://www.bksv.com

[12] T. Schultz, Community Noise Ratings, Essex: Applied Science Publishers Ltd, 1982.

[13] H. T. T. Phan, T. Yano, H. A. T. Phan, T. Nishimura, T. Sato, and Y. Hashimoto, "Community responses to road traffic noise in Hanoi and Ho Chi Minh City," Applied Acoustics, vol. 71, pp. 107-114, 2010.

[14] World Health Organization and European Centre for Environment and Health, Report on the Technical Meeting of Exposure-Response Relationships of Noise on Health, Germany: Bonn, 2003.

[15] W. J. Cavanaugh and G. C. Tocci, "Environmental noise: The invisible pollutant" ESC, vol. 1, USC Institute of Public Affairs, 1998.

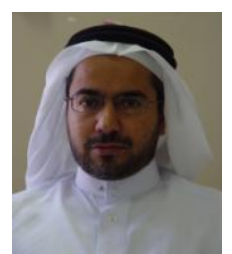

Khalid A. Alsaif is a faculty member of the Mechanical Engineering Department at King Saud University and a consultant at Kacst, Saudi Arabia. He earned his Ms. and Ph.D degrees from University of Wisconsin-Madison, USA in the field of mechanical design, flow induced vibrations, and nonlinear dynamics. He is involved in design of mechanical systems, instrumentation and experiments, vibration control techniques, low earth orbit satellite design and remote monitoring systems development. His experience includes micro-satellite projects management and system engineering development. His research activities include nonlinear dynamics, earthquake engineering, flow induced vibrations, micro-satellite structural design \& dynamics and vibration control. He offered several short courses in microsatellite subsystems, which include satellite communications, power and thermal subsystem, mechanical structure, and attitude determination and control system.

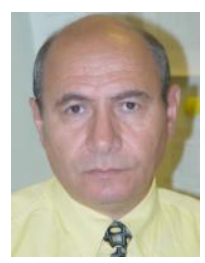

Mosaad A. Foda was born in February 1948 in Mansoura, Egypt. He received his bachelor and master degrees in mechanical engineering from Cairo University in 1971 and 1976, respectively. He received the M.Sc and Ph.D degrees in mechanical engineering from Georgia Institute of Technology, USA in 1982 and 1984, respectively. He was a Fulbright and Alexander von Humboldt scholar in USA and in Germany; respectively. Since 1994, he has been a professor at King Saud University, Saudi Arabia. Dr. Foda has many publications in the area of engineering acoustics, wave propagation (both linear and nonlinear), noise control, composite materials, vibrations, satellite dynamics, control and nanosciences. 